\title{
BMJ Open Workplace violence and its aftermath in China's health sector: implications from a cross-sectional survey across three tiers of the health system
}

\author{
Sheng Zhi Yang, ${ }^{\oplus 1}$ Dan Wu, ${ }^{2}$ Nan Wang, ${ }^{1}$ Therese Hesketh, ${ }^{3,4}$ Kai Sing Sun, ${ }^{5}$ \\ $\mathrm{Lu} \mathrm{Li}^{1}{ }^{1}$ Xudong Zhou ${ }^{1}$
}

To cite: Yang SZ, Wu D, Wang N, et al. Workplace violence and its aftermath in China's health sector: implications from a cross-sectional survey across three tiers of the health system. BMJ Open 2019;9:e031513. doi:10.1136/ bmjopen-2019-031513

\section{- Prepublication history for} this paper is available online. To view these files, please visit the journal online (http://dx.doi. org/10.1136/bmjopen-2019031513).

SZY and DW are joint first authors.

Received 08 May 2019 Revised 14 August 2019 Accepted 19 August 2019
Check for updates

(C) Author(s) (or their employer(s)) 2019. Re-use permitted under CC BY-NC. No commercial re-use. See rights and permissions. Published by BMJ.

For numbered affiliations see end of article.

Correspondence to

Dr Xudong Zhou;

zhouxudong@zju.edu.cn

Professor Lu Li; lilu@zju.edu.cn

\section{ABSTRACT}

Objectives To determine the prevalence of physical violence and threats against health workers and the aftermath in tertiary, secondary and primary care facilities in China.

Design A cross-sectional questionnaire study. Setting 5 tertiary hospitals, 8 secondary hospitals and 32 primary care facilities located in both urban and rural areas of Zhejiang Province, China, were chosen as the study sites.

Participants A total of 4862 health workers who have contact with patients completed a survey from July 2016 to July 2017.

Outcome measures The prevalence of physical violence, threats and Yi Nao, specific forms of physical violence and their aftermath were measured by a self-designed and verified questionnaire. Multivariable logistic regression models were used to examine the association between perceived organisational encouragement of reporting workplace violence (WPV) and physical violence, threats and Yi Nao after controlling for age, sex, level of facility, professional ranking and type of health worker.

Results Among all respondents, 224 (4.6\%) were physically attacked and 848 (17.4\%) experienced threats in the past year. Respondents in secondary hospitals were more likely to experience physical violence ( $\mathrm{AOR}=3.29,95 \% \mathrm{Cl} 2.21$ to 4.89), threats ( $\mathrm{AOR}=1.61$, $95 \% \mathrm{Cl} 1.32$ to 1.98$)$ and $\mathrm{Yi} \mathrm{NaO}(\mathrm{AOR}=2.47,95 \% \mathrm{Cl} 2.10$ to 2.91 ), compared with primary care providers. Lack of organisational policies to report WPV was associated with higher likelihood of physical violence (AOR=3.64, $95 \% \mathrm{Cl} 2.57$ to 5.18$)$ and threats (AOR=2.21, 95\% $\mathrm{Cl} 1.76$ to 2.78 ). Among physical violence cases, only $29.1 \%$ reported the attack to police mainly because most felt it useless to do so (58.8\%). Only $25.7 \%$ were investigated and $72.4 \%$ of attackers received no punishment. Of all those attacked or threatened, $59.4 \%$ wanted to quit current post and $76.0 \%$ were fearful of dealing with urgent or severe cases.

Conclusions Proper management of the aftermath of violence against health workers is inadequate. Formal guidelines for reporting and managing WPV are urgently needed.
Strengths and limitations of this study

- Health workers from health facilities of all three levels in China were sampled to draw a whole picture of prevalence, correlates and reasons for workplace violence (WPV) against health workers in this study.

- This study achieved a larger sample size (4862) and a higher valid response rate $(79.8 \%)$ than past studies related to WPV against health workers.

- The convenience sampling strategy of this study may compromise the representativeness of the sample.

- A single Yi Nao incident usually affects a larger number of health workers in the facility, and thus, there might be potential impacts of $\mathrm{Yi}$ Nao at organisational level that could not be identified in the current study.

\section{INTRODUCTION}

Workplace violence (WPV) against health workers has become a major global health problem. ${ }^{1}$ It finds its expression in verbal abuse, bullying, threats, sexual harassment, physical assault and homicide. ${ }^{2}$ WPV has threatened health workers' well-being, safety, health and even their lives, and has also resulted in a tendency to defensive medicine, poorer health service quality and productivity, resignation of health personnel and difficulties in recruitment. ${ }^{2-4}$ This study focused on client-initiated WPV (ie, assaults by patients, caregivers or relatives of the patient) because it is the most common type of WPV in the health sector. ${ }^{4}$

China is known to have a high prevalence of WPV in the health sector. ${ }^{5-7}$ A survey organised by the Chinese Hospital Association which drew data from 316 hospitals showed that the proportion of hospitals experiencing WPV increased from $90 \%$ in 2008 to $96 \%$ in 2012. ${ }^{8}$ A study conducted by the Chinese Medical Doctor Association in 2014 revealed 
that nearly three quarters of physicians ever experienced physical injuries or verbal abuse at work. ${ }^{9}$ China issued an Amendment of Criminal Law which included regulations against WPV in the health sector in $2015 .{ }^{10}$ This amendment might explain the results of a widely circulated study conducted from 2013 to 2017 which showed that WPV in the health sector reached a peak in 2015 and then began to decrease. ${ }^{11}$ Nevertheless, a 2016 survey with 1024 Chinese nurses showed $75.4 \%$ of physicians had experienced at least one form of WPV, ${ }^{12}$ and a 2017 study indicated that $66 \%$ of participants had experienced WPV in the past year. ${ }^{13}$ The WPV against health workers remains widespread even after the law legislations, and medical professions are considered by many to be unsafe working environments. ${ }^{71013}$

The prominent problem of WPV in China is believed to be related to systemic and historical factors. ${ }^{1415}$ Insufficient public funding into the public health sector, commercialisation of public health facilities, and high out-of-pocket payment contributed to patient dissatisfaction with public health services over time, leading to a distrust of healthcare professionals and poor doctor-patient relationships. ${ }^{16}$ Legal channels for reporting malpractice or resolving medical disputes are perceived to be time-consuming, unaffordable, ineffective and unfair. ${ }^{8}{ }^{17}$ Biassed media reports may also exacerbate the tension. ${ }^{15} 18$ The Chinese government started a massive healthcare reform in 2009, rolled out universal health insurance coverage and zero-profit drug policy aiming to improve accessibility and affordability of health services. ${ }^{19-21}$ However, with health resources remaining insufficient and the structural imbalance among the three tiers of healthcare facilities, ${ }^{22} 23$ namely tertiary hospitals, secondary hospitals and primary care facilities, patients in China still flood into major hospitals and deal with long waiting times ${ }^{15}$ and inadequate communication from physicians. ${ }^{24}$ The accumulation of these patients' poor experiences can instigate more tension between health providers and patients. ${ }^{25}$ Previous researches conducted in tertiary hospitals and/ or together with secondary hospitals found that there is a high prevalence of WPV against health workers. ${ }^{6} 1326$ Seldom have these studies compared rates of WPV within the three-tier health system structure in China, and WPV in a rapidly changing health system merits more research.

Former studies have identified different kinds of WPV. One large sample survey of WPV in China from 2016 recognised seven types of WPV, ${ }^{27}$ which include some special types such as 'smear reputation' and 'mobbing behaviour' ${ }^{28}$ Most Chinese studies only described WPV in the most general terms or divided into physical violence, verbal violence and sexual harassment. ${ }^{13262829}$ In all these types of WPV, the prevalence of physical violence and its correlates have been frequently studied. However, little is known about specific forms of physical violence in China. On the other hand, threats of physical violence are a form of psychological violence. ${ }^{2}$ Threats are associated with a higher risk of actual physical violence. ${ }^{30}$ The self-rated degree of seriousness of the threat incident outcomes was similar to that of actual physical violence, and threats can cause consequences comparable to actual physical violence. ${ }^{31}$ Specific data about threats and their associated factors in healthcare settings are needed. In addition, Yi Nao is a unique form of WPV in China, and has been defined as an extreme and organised form of WPV in which patients, relatives and even hired gangs attack health workers, damage hospital facilities and disturb the running of hospitals in order to gain monetary compensation from the hospital. ${ }^{18}$ Many health workers have had individual exposure to $\mathrm{Yi}$ Nao by either witnessing or falling victim to it, but little is known about its correlates in the Chinese setting.

Furthermore, how employees perceive organisational policies and practices to prevent aggression is important because it affects victims' willingness to report violent cases to relevant parties. ${ }^{31}$ It would be useful to conduct more research on the relationship between physicians' perception of organisational policies to report WPV and the rates at which they experienced incidents of WPV. In this study, we aimed to (1) Examine the magnitude of physical violence, threats, Yi Nao and their correlates, at the three levels of healthcare facilities in China. (2) Examine specific forms of physical violence and the aftermath. (3) Perception of organisational policies to report WPV and its association with physical violence, threats and Yi Nao.

\section{METHODS}

\section{Study population and design}

The study was a cross-sectional survey conducted from July 2016 to July 2017 in Zhejiang Province, which has a population of 56 million people including half a million health sector workers. ${ }^{32}{ }^{33}$ The target population was all health workers who had patient contact. The sampling strategy was divided into two steps:

First, we stratified the sampling by facility type which has been built according to political administration levels. Specifically, primary care facilities provide primary healthcare to the population of a district or a town, while tertiary and secondary hospitals are usually located in cities and counties, aiming to provide referral care to the population residing in their administrative areas. We purposefully sampled tertiary and secondary hospitals across different cities and counties. We included general hospitals and specialty hospitals. The latter included women and children hospitals, and traditional Chinese medicine hospitals.

The selected health facilities included tertiary hospitals (mostly in the developed capital city of Hangzhou and prefecture-level cities), secondary hospitals (mostly in counties) and primary care facilities including urban community health centres and rural township health centres. Specifically, the selected health facilities at each tier included: (1) Five tertiary hospitals: one general hospital was selected in Hangzhou, a developed prefecture-level city Jiaxing, and a less developed city Quzhou, 
respectively; one women and children hospital and one traditional Chinese medicine hospital in Hangzhou were selected. (2) Eight secondary hospitals: one general hospital and one traditional Chinese medicine hospital were sampled from the developed counties Ninghai and Shenzhou, and the less developed counties Jiangshan and Kaihua, respectively. (3) Thirty-two primary care facilities including 16 urban community health centres in Hangzhou and Ningbo (8 in each city) and 16 rural township health centres in Ninghai and Jiangshan (8 in each county). A total of 46 health facilities were selected for the study.

Second, we used convenience sampling to recruit participants. We first obtained permission from hospital managers or primary care facility directors to conduct the survey. Afterwards, an administrator was designated to help us contact each unit or contact health workers. We invited health workers on duty on surveying days to fill in the questionnaire, including doctors, nurses, laboratory technicians (who need to dispense sample containers and collect biological samples from patients) and administrative staff who had patient contact in their daily practices. The purpose of the survey was fully explained, and verbal consent was obtained. The front page of the questionnaire also included a statement of consent. Anonymity and confidentiality were assured. We informed participants that the survey was fully voluntary.

\section{Questionnaire}

The questionnaire was designed based on WHO's instrumental survey tools which have previously been used in China. ${ }^{2} 34$ The original questionnaire was developed by the joint programme on WPV in the health sector among the International Labour Office, International Council of Nurses, WHO and Public Services International in 2003. It consists of five sections: personal and workplace data, physical WPV, psychological WPV, health sector employer, and opinions on WPV. In this study, we adapted our questionnaire based on the former two and the last sections with a focus on physical violence. To fit the study aims and reflect the Chinese setting, additional items were added, including two items about experience of threats and Yi Nao, four items about specific forms of physical violence and how victims respond, and six items about the aftermath.

The final questionnaire comprised five sections: (1) Sociodemographic information and professional background. (2) Experience of physical violence, threats of physical violence (defined in the questionnaire as threats of physical violence against targeted individuals, with or without weapons, resulting in fear of physical harm or other negative impacts on the targeted individuals), and some form of exposure to, that is witnessing or experiencing, Yi Nao in the last year before the survey. (3) Specific forms of physical violence, victims responses and consequences to the perpetrators. (4) Aftermath of physical violence and threats. (5) Perception of organisational policies to report WPV.

\section{Data analysis}

Descriptive analyses were conducted. Pearson's chi-square test and Fisher's exact test were used to test the differences in WPV between subgroups. Multivariable logistic regression examined the association between perceived organisational encouragement of reporting WPV and physical violence, threats and Yi Nao after controlling for age, sex, level of facility, professional ranking and type of health worker. A P value of $<0.05$ was considered statistically significant. Statistical analysis was conducted using SPSS V.25.

\section{Patient and public involvement}

No patients were involved in the design, recruitment and conduct of the study. The study participants and their facilities were offered a summary of the study's results.

\section{RESULTS}

\section{Sample characteristics and perception of organisational reporting policy $(\mathrm{n}=4862)$}

We distributed 6089 questionnaires, of which 5145 were returned. Among them, 283 were considered invalid due to missing values of key variables, resulting in a valid response rate of $79.8 \%(4862 / 6089)$. Sample characteristics are shown in table 1 . We sampled similar numbers of respondents across the three levels of facilities: tertiary $(1873,38.5 \%)$, secondary $(1509,31.0 \%)$ and primary $(1480,30.4 \%)$. The mean age of the respondents was 33.7 years $(\mathrm{SD}=8.6)$, and 3551 respondents $(73.0 \%)$ were female. Out of all respondents, 1954 (40.2\%) were doctors, 1911 (39.3\%) were nurses, $692(14.3 \%)$ were laboratory staff and $299(6.2 \%)$ were administrators. A total of $2205(45.5 \%)$ were junior staff and 1571 (32.4) were intermediate. In the past year, $224(4.6 \%)$ of the respondents were physically attacked, 848 (17.4\%) experienced threats and 1956 (40.4\%) had some exposure (witnessing or experiencing) to a Yi Nao incident in their facility. Over half of the respondents (56.6\%) reported organisational encouragement to report WPV, but the rest either did not perceive such encouragement (487, $10 \%)$ or were unaware of such an organisational atmosphere (1609, 33.2\%).

\section{Characteristics of physical violence $(n=224)$}

The characteristics of physical violence are indicated in table 2. Among 224 health workers who experienced physical violence in the past year, $107(47.8 \%)$ were pushed, $32(14.3 \%)$ were beaten up, $28(12.5 \%)$ were attacked by perpetrators using implements, $23(10.3 \%)$ were kicked and $1(0.4 \%)$ was stabbed. Nineteen respondents $(8.5 \%)$ reported slapping, $20(8.9 \%)$ punching, $14(6.3 \%)$ strangling, $12(5.4 \%)$ pulling hair, $11(4.9 \%)$ scratching and $3(1.3 \%)$ stamping. A hundred and sixty $(71.7 \%)$ of the perpetrators were the patient's relatives or friends, and 12 (5.4\%) involved Yi Nao events. Among all, 64 (28.6\%) reported physical injuries due to the violence. Among 12 cases involving Yi Nao, 9 (75.0\%) caused physical injuries 
Table 1 Demographics and professional characteristics of health workers who reported physical violence, threats or Yi Nao in the past year in Zhejiang, China

\begin{tabular}{|c|c|c|c|c|}
\hline & $\begin{array}{l}\text { Total } \\
(\%)(n=4862)\end{array}$ & $\begin{array}{l}\text { Physical violence } \\
(\%)(n=224)\end{array}$ & $\begin{array}{l}\text { Threats of } \\
\text { physical violence } \\
(\%)(n=848)\end{array}$ & $\begin{array}{l}\text { Yi Nao (\%) } \\
(n=1956)\end{array}$ \\
\hline \multicolumn{5}{|l|}{ Age } \\
\hline Mean (SD) & $33.7(8.6)$ & $34.9(8.5)$ & $34.5(7.9)$ & $33.9(8.1)$ \\
\hline \multicolumn{5}{|l|}{ Sex } \\
\hline Male & $1295(26.7)$ & 99 (44.6) & 277 (32.7) & $625(32.1)$ \\
\hline Female & 3551 (73.3) & $123(55.4)$ & $570(67.3)$ & $1325(67.9)$ \\
\hline \multicolumn{5}{|l|}{ Level of facility } \\
\hline Tertiary hospitals & $1873(38.5)$ & 67 (29.9) & $315(37.1)$ & 765 (39.1) \\
\hline Secondary hospitals & $1509(31.0)$ & 120 (53.6) & $323(38.1)$ & 765 (39.1) \\
\hline Primary care facilities & $1480(30.4)$ & 37 (16.5) & $210(24.8)$ & $426(21.8)$ \\
\hline \multicolumn{5}{|l|}{ Type of health workers } \\
\hline Doctors & $1954(40.2)$ & $118(52.7)$ & $398(47.0)$ & $898(46.0)$ \\
\hline Nurses & $1911(39.4)$ & 78 (34.8) & $328(38.7)$ & $755(38.7)$ \\
\hline Laboratory & $692(14.3)$ & $20(8.9)$ & $95(11.2)$ & $221(11.3)$ \\
\hline Administrators & $299(6.2)$ & $8(3.6)$ & $26(3.1)$ & $78(4.0)$ \\
\hline \multicolumn{5}{|l|}{ Professional ranking } \\
\hline Junior & $2205(45.5)$ & $94(42)$ & $344(40.6)$ & $821(42.1)$ \\
\hline Intermediate & $1571(32.4)$ & $84(37.5)$ & $320(37.8)$ & $678(34.7)$ \\
\hline Senior & $579(11.9)$ & $33(14.7)$ & $140(16.5)$ & 303 (15.5) \\
\hline None & $496(10.2)$ & $13(5.8)$ & $43(5.1)$ & $150(7.7)$ \\
\hline \multicolumn{5}{|c|}{ Encourage reporting violence in the facility } \\
\hline No & $487(10.0)$ & $62(27.7)$ & $141(16.7)$ & $282(14.4)$ \\
\hline Yes & $2752(56.8)$ & $101(45.1)$ & $423(50.1)$ & 1058 (54.1) \\
\hline Don't know & $1609(33.2)$ & $61(27.2)$ & $281(33.3)$ & $615(31.5)$ \\
\hline
\end{tabular}

$\%$ : valid percentages.

${ }^{*}$ Column frequencies do not add up to the total due to missing values.

to victims, compared with 55 out of 205 (26.8\%) without Yi Nao involvement.

The immediate responses of the victims included 7 (3.2\%) swearing, 19 (8.6\%) fighting back and 109 (49.3\%) trying to calm down the perpetrators. After the incident, $64(29.1 \%)$ reported their experiences to the police; 122 $(55.5 \%)$ reported to senior doctors/the hospital, only 1 $(0.4 \%)$ reported to medical association and $34(15.5 \%)$ took no action at all. Among the 153 respondents who explained their reasons for not reporting their experiences to the police, $90(58.8 \%)$ felt it useless to do so, 32 $(20.9 \%)$ did not know who to report to and $28(18.3 \%)$ thought it was too much trouble. Totally, $56(25.7 \%)$ of the physical violence cases were investigated and most $(37 / 56,66.1 \%)$ were conducted by hospitals. A total of $157(72.4 \%)$ of the attackers received no punishment, and these included the stabbing case causing physical injury, 9/14 (64.3\%) who strangled, 12/19 (63.2\%) who punched, 14/23 (60.9\%) who kicked and 21/27 (77.8\%) who had used implements. Only $60(27.6 \%)$ received some form of punishment, including 27 (12.4\%) being verbally warned, $19(8.8 \%)$ detained for a short time in prison and $3(1.4 \%)$ sentenced. Only $7 / 12$ (58.3\%) physical violence cases involving Yi Nao were reported to the police and 10/12 $(83.3 \%)$ of these perpetrators were not punished. Only $11 / 224(4.9 \%)$ were satisfied with how the incident was handled.

\section{Impact of physical violence or threats $(\mathrm{n}=1072)$}

Table 3 demonstrates that among 1072 health workers who experienced physical violence or threats, 835 (79.9\%) had repeated, disturbing memories, thoughts or images of the attack; $653(62.8 \%)$ avoided thinking about or talking about the attack; $1000(95.5 \%)$ were 'super-alert' or more vigilant; $873(83.5 \%)$ considered how to protect themselves while seeing patients; $826(79.0 \%)$ trusted patients less; $791(76.0 \%)$ were fearful of dealing with urgent or severe cases; and 618 (59.4\%) wanted to quit their current post. Nearly a fifth had to take some time off work due to the incident. There were no significant differences in these impacts between those who experienced physical violence and those who encountered threats. 
Table 2 Characteristics of physical violence incidents against health workers in Zhejiang, China $(n=224)$

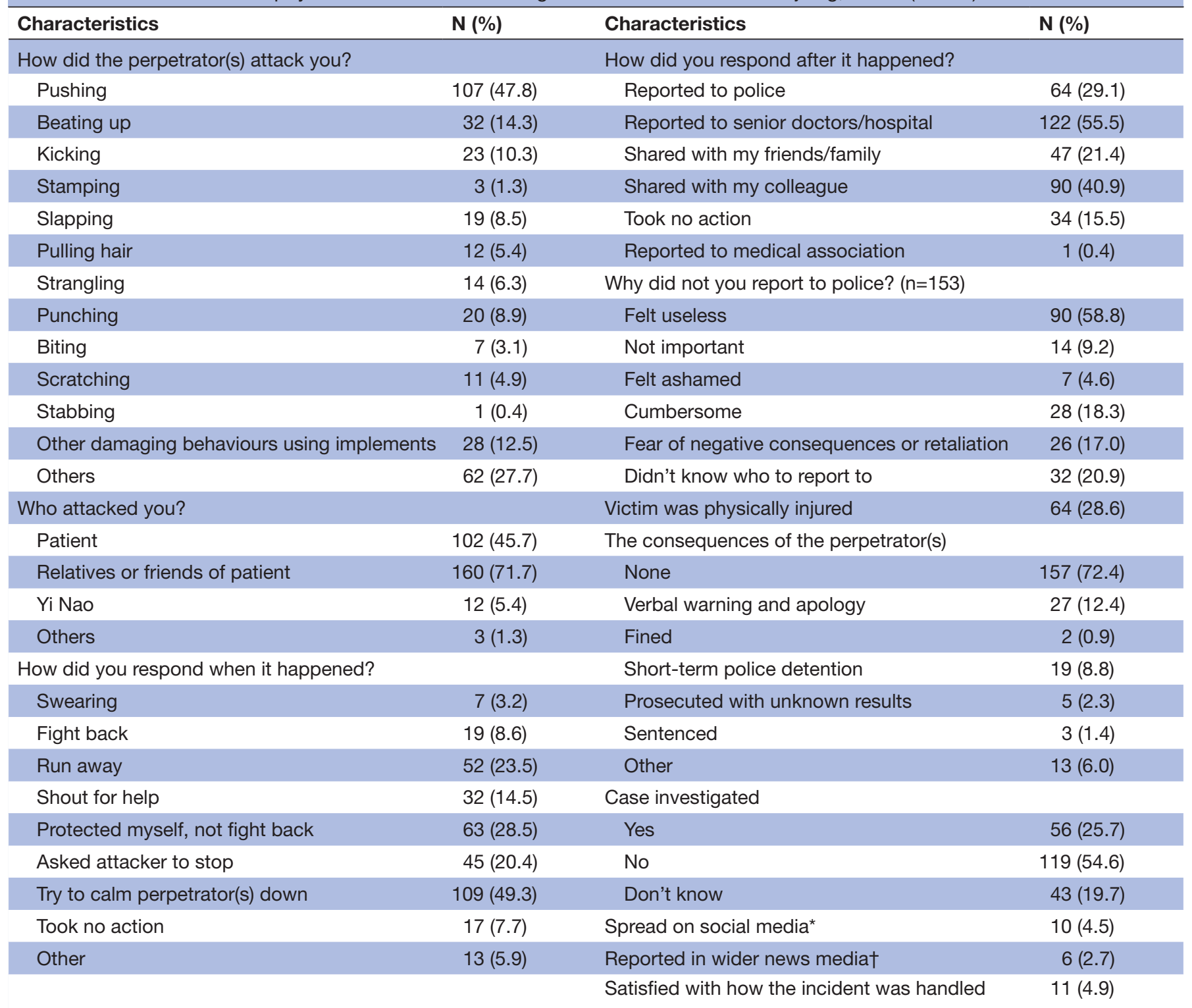

$\%$ : valid percentages.

${ }^{*}$ Common social media platforms included Weibo (microblog similar to Twitter), $Q Q$ and WeChat (instant messaging and social networking mobile phone applications which are similar to Facebook).

†This included news websites or traditional news media like TV and newspapers.

Correlates of physical violence, threats and exposure to Yi Nao The correlates of physical violence, threats and exposure to $\mathrm{Yi} \mathrm{Nao}$ are presented in table 4. Male health workers were more likely than female to report that they had experienced physical violence (adjusted $\mathrm{OR}$, or $\mathrm{AOR}=2.18$, $95 \%$ CI 1.53 to 3.12 ), threats (AOR $=1.33,95 \%$ CI 1.10 to 1.62) and exposure to Yi Nao (AOR=1.42, 95\% CI 1.22 to 1.66). Health workers in secondary hospitals had a higher risk of experiencing physical violence ( $\mathrm{AOR}=3.29,95 \% \mathrm{CI}$ 2.21 to 4.89 ), threats (AOR=1.61, 95\% CI 1.32 to 1.98 ) and $\mathrm{Yi}$ Nao (AOR=2.47, 95\% CI 2.10 to 2.91) compared with those in primary care facilities. Health workers in tertiary hospitals were more likely than primary care health workers to report threats $(\mathrm{AOR}=1.28,95 \%$ CI 1.04 to 1.57 ) and Yi Nao exposure (AOR=1.68, 95\% CI 1.44 to 1.97$)$. Health workers who did not perceive organisational policies to report WPV were more likely to have experienced physical violence $(\mathrm{AOR}=3.64,95 \% \mathrm{CI} 2.57$ to 5.18$)$, threats $(\mathrm{AOR}=2.21,95 \% \mathrm{CI} 1.76$ to 2.78$)$ and $\mathrm{Yi}$ Nao $(A O R=2.26,95 \%$ CI 1.84 to 2.78$)$.

\section{DISCUSSION}

High prevalence of WPV in the health sector represents a major public health challenge in China. We examined physical violence, threats and Yi Nao against health workers at three tiers of health facilities in Zhejiang province. The study extends the literature by demonstrating 
Table 3 Impact of physical violence or threats on victims in the health sector in Zhejiang, China

\begin{tabular}{|c|c|c|c|}
\hline & $\begin{array}{l}\text { Total }(\%) \\
(\mathrm{n}=1072)\end{array}$ & $\begin{array}{l}\text { Physical violence }(\%) \\
(\mathrm{n}=224)\end{array}$ & $\begin{array}{l}\text { Threats }(\%) \\
(\mathrm{n}=848)\end{array}$ \\
\hline $\begin{array}{l}\text { Repeated, disturbing memories, thoughts or images of the } \\
\text { attack }\end{array}$ & 835 (79.9) & $169(77.9)$ & $666(80.4)$ \\
\hline Made you trust less in patients as a whole & $826(79.0)$ & $161(75.2)$ & $665(79.9)$ \\
\hline Avoiding thinking about or talking about the attack & $653(62.8)$ & $125(58.7)$ & $528(63.9)$ \\
\hline Being 'super-alert' or watchful and on guard & $1000(95.5)$ & $201(93.1)$ & $799(96.1)$ \\
\hline Often consider how to protect yourself while seeing patients & $873(83.5)$ & $189(87.5)$ & $684(82.5)$ \\
\hline Wanting to quit the current post & $618(59.4)$ & $131(61.5)$ & $487(58.9)$ \\
\hline Took some time off from work after being attacked & $185(18.0)$ & $46(21.0)$ & $139(17.1)$ \\
\hline
\end{tabular}

$\%$ : valid percentages.

that health workers at secondary and tertiary hospitals were at a higher risk of physical violence, threats and exposure to Yi Nao, and widespread impunity of perpetrators. In addition, lack of organisational encouragement to report WPV was associated with a higher risk of physical violence, threats and Yi Nao.

The prevalence of physical violence in this study was $4.6 \%$, which was lower than that of previous studies in China ${ }^{6273536}$ but still higher than other countries. ${ }^{37}$ Our study also found high rates of physical violence threats and exposure to Yi Nao. There were $17.4 \%$ of participants who encountered threats while $40.4 \%$ of them witnessed or experienced an incident of $\mathrm{Yi} \mathrm{NaO}$ in the past year. Besides, the overwhelming majority of the victims of physical violence and threats became vigilant in the clinical environment and worried about personal safety while seeing patients. We found that health workers in secondary hospitals were more likely to have directly encountered physical violence with the prevalence of $8.0 \%$ than those who worked in primary care facilities with a prevalence of $2.5 \%$. And compared with health workers in primary care facilities, those in secondary and tertiary hospitals were at a higher risk of receiving threats and being exposed to Yi Nao. There are two potential explanations for such a trend. First, there was a greater chance of dealing with patients with more severe illnesses, and mismatching patient expectations and consequent patient frustration put higher-level facilities at higher risk than primary care facilities. A study conducted in Thailand reported that the severity of a patient's illness is an important contributing factor to physical violence initiated by the patient. ${ }^{38}$ Unmet expectations were identified as a major reason for assaults. ${ }^{39}$ Resolving the mismatch between patient expectations and care delivered is an important strategy to prevent WPV. ${ }^{40}$ Unreasonably high patient expectations, however, were also reported by a previous Chinese study, ${ }^{41}$ indicating that, in addition to providing adequate explanations to patients, proper management of unrealistic expectations may be necessary to reduce WPV.

Second, health workers with better education and advanced medical equipment are concentrated in top tier hospitals. ${ }^{42}$ Primary care facilities are relatively underused due to less competitivity and patient trust compared with higher level facilities. ${ }^{43}{ }^{44}$ Many patients sought care even for simple common conditions at outpatient services of tertiary and secondary hospitals. This shortens the consultation time for each patient, which may compromise the quality of care and patients' satisfaction. ${ }^{44}{ }^{45}$ Improving primary care quality and increasing its utilisation may be an essential, long-term strategy to tackle the underlying factors of WPV from the health system perspective.

Our study also found that incidents of physical violence are severely under-reported to relevant authorities or organisations, despite the fact that reporting experiences of violence is an essential part of a successful WPV prevention programme. ${ }^{46}$ Less than $30 \%$ of victims reported their experiences to police and only $25.7 \%$ of the cases were investigated in some way. Impunity to perpetrators of physical violence was also widespread. In physical violence cases, more than $70 \%$ of the perpetrators were left unpunished, including those who committed severe forms of physical violence such as stabbing, strangling, kicking and damaging behaviours using implements. As for those cases involving Yi Nao, over $80 \%$ of the perpetrators were not punished. Overall, only $4.9 \%$ of victims suffering physical violence were satisfied with how their cases were handled.

Major reasons for under-reporting and impunity may be related to poor law enforcement against physical violence in the health sector and inadequate organisational support or advocacy to reporting WPV in their health facilities. Among the victims who did not report the incident to the police, more than a fifth did not know who to report to and nearly $60 \%$ felt useless to do so. Health workers are generally believed to be more powerful due to the information asymmetry, ${ }^{8}$ and patients are deemed as more vulnerable. Patient violence against health workers is often regarded by the public as an understandable manifestation of grievance or self-protection. ${ }^{47}$ To meet socially desirable expectations, police authorities and hospital leaders often adopt tolerant attitudes towards patient perpetrators. Law enforcement professionals also tend to regard WPV against health workers as a simple doctor-patient relationship problem 
Table 4 Correlates of physical violence, threats and exposure to Yi Nao among health workers in China

\begin{tabular}{|c|c|c|c|c|c|c|c|c|c|c|c|c|}
\hline & \multicolumn{4}{|c|}{ Physical violence } & \multicolumn{4}{|c|}{ Threats of physical violence } & \multicolumn{4}{|c|}{ Exposure to Yi Nao } \\
\hline & $\begin{array}{l}\text { OR } \\
(95 \% \mathrm{Cl})\end{array}$ & $P$ value & $\begin{array}{l}\text { AOR } \\
(95 \% \mathrm{Cl}) \dagger\end{array}$ & $P$ value & $\begin{array}{l}\text { OR } \\
(95 \% \mathrm{Cl})\end{array}$ & $P$ value & $\begin{array}{l}\text { AOR } \\
(95 \% \mathrm{Cl}) \dagger\end{array}$ & $P$ value & $\begin{array}{l}\text { OR } \\
(95 \% \mathrm{Cl})\end{array}$ & $P$ value & $\begin{array}{l}\text { AOR } \\
(95 \% \mathrm{Cl}) \dagger\end{array}$ & $P$ value \\
\hline Age & $\begin{array}{l}1.02 \\
(1.00 \text { to } \\
1.03)^{\star}\end{array}$ & 0.034 & $\begin{array}{l}1.00 \\
(0.98 \text { to } \\
1.03)\end{array}$ & 0.689 & $\begin{array}{l}1.01 \\
(1.00 \text { to } \\
1.02)^{\star \star}\end{array}$ & 0.002 & $\begin{array}{l}0.99 \\
(0.97 \text { to } \\
1.00)\end{array}$ & 0.074 & $\begin{array}{l}1.01 \\
(1.00 \text { to } \\
1.01)\end{array}$ & 0.129 & $\begin{array}{l}0.98 \\
(0.97 \text { to } \\
0.99)^{\star \star \star}\end{array}$ & $<0.001$ \\
\hline \multicolumn{13}{|l|}{ Sex } \\
\hline \multicolumn{13}{|l|}{ Level of facility } \\
\hline Primary care & Ref & & & & & & & & & & & \\
\hline $\begin{array}{l}\text { Secondary } \\
\text { hospitals }\end{array}$ & $\begin{array}{l}3.37 \\
(2.31 \text { to } \\
4.91)^{\star \star \star}\end{array}$ & $<0.001$ & $\begin{array}{l}3.29 \\
(2.21 \text { to } \\
4.89)^{\star \star \star}\end{array}$ & $<0.001$ & $\begin{array}{l}1.65 \\
(1.36 \text { to } \\
1.99)^{\star \star \star}\end{array}$ & $<0.001$ & $\begin{array}{l}1.61 \\
(1.32 \text { to } \\
1.98)^{\star \star \star}\end{array}$ & $<0.001$ & $\begin{array}{l}2.57 \\
(2.21 \text { to } \\
2.99)^{\star \star \star}\end{array}$ & $<0.001$ & $\begin{array}{l}2.47 \\
(2.10 \text { to } \\
2.91)^{\star \star \star}\end{array}$ & $<0.001$ \\
\hline \multicolumn{13}{|c|}{ Types of health workers } \\
\hline Nurses & Ref & & & & & & & & & & & \\
\hline Doctors & $\begin{array}{l}1.51 \\
(1.13 \text { to } \\
2.03)^{\star \star}\end{array}$ & 0.006 & $\begin{array}{l}1.02 \\
(0.69 \text { to } \\
1.51)\end{array}$ & 0.908 & $\begin{array}{l}1.23 \\
(1.05 \text { to } \\
1.45)^{\star}\end{array}$ & 0.011 & $\begin{array}{l}1.07 \\
(0.87 \text { to } \\
1.30)\end{array}$ & 0.536 & $\begin{array}{l}1.30 \\
(1.15 \text { to } \\
1.48)^{\star \star \star}\end{array}$ & $<0.001$ & $\begin{array}{l}1.17 \\
(1.00 \text { to } \\
1.37)\end{array}$ & 0.053 \\
\hline Laboratory & $\begin{array}{l}0.70 \\
(0.42 \text { to } \\
1.15)\end{array}$ & 0.160 & $\begin{array}{l}0.57 \\
(0.33 \text { to } \\
0.98)^{\star}\end{array}$ & 0.044 & $\begin{array}{l}0.77 \\
(0.60 \text { to } \\
0.98)^{*}\end{array}$ & 0.036 & $\begin{array}{l}0.78 \\
(0.59 \text { to } \\
1.02)\end{array}$ & 0.064 & $\begin{array}{l}0.72 \\
(0.60 \text { to } \\
0.87)^{\star \star}\end{array}$ & 0.001 & $\begin{array}{l}0.74 \\
(0.60 \text { to } \\
0.91)^{\star \star}\end{array}$ & 0.004 \\
\hline Administrators & $\begin{array}{l}0.65 \\
(0.31 \text { to } \\
1.35)\end{array}$ & 0.246 & $\begin{array}{l}0.69 \\
(0.30 \text { to } \\
1.58)\end{array}$ & 0.362 & $\begin{array}{l}0.46 \\
(0.30 \text { to } \\
0.70)^{\star \star \star}\end{array}$ & $<0.001$ & $\begin{array}{l}0.62 \\
(0.40 \text { to } \\
0.96)^{\star}\end{array}$ & 0.035 & $\begin{array}{l}0.54 \\
(0.41 \text { to } \\
0.71)^{\star \star \star}\end{array}$ & $<0.001$ & $\begin{array}{l}0.69 \\
(0.51 \text { to } \\
0.94)^{\star}\end{array}$ & 0.022 \\
\hline None & $\begin{array}{l}0.60 \\
(0.34 \text { to } \\
1.09)\end{array}$ & 0.119 & $\begin{array}{l}0.75 \\
(0.41 \text { to } \\
1.40)\end{array}$ & 0.351 & $\begin{array}{l}0.51 \\
(0.37 \text { to } \\
0.72)^{\star \star \star}\end{array}$ & $<0.001$ & $\begin{array}{l}0.53 \\
(0.37 \text { to } \\
0.75)^{\star \star \star}\end{array}$ & $<0.001$ & $\begin{array}{l}0.73 \\
(0.59 \text { to } \\
0.91)^{\star \star}\end{array}$ & 0.022 & $\begin{array}{l}0.75 \\
(0.60 \text { to } \\
0.94)^{\star}\end{array}$ & 0.045 \\
\hline \multicolumn{13}{|c|}{ Encourage reporting violence in the facility } \\
\hline Yes & Ref & & & & & & & & & & & \\
\hline No & $\begin{array}{l}3.83 \\
(2.75 \text { to } \\
5.34)^{\star \star \star}\end{array}$ & $<0.001$ & $\begin{array}{l}3.64 \\
(2.57 \text { to } \\
5.18)^{\star \star \star}\end{array}$ & $<0.001$ & $\begin{array}{l}2.24 \\
(1.80 \text { to } \\
2.80)^{\star \star \star}\end{array}$ & $<0.001$ & $\begin{array}{l}2.21 \\
(1.76 \text { to } \\
2.78)^{\star \star \star}\end{array}$ & $<0.001$ & $\begin{array}{l}2.22 \\
(1.82 \text { to } \\
2.70)^{\star \star \star}\end{array}$ & $<0.001$ & $\begin{array}{l}2.26 \\
(1.84 \text { to } \\
2.78)^{\star \star \star}\end{array}$ & $<0.001$ \\
\hline Don't know & $\begin{array}{l}1.03 \\
(0.75 \text { to } \\
1.43)\end{array}$ & 0.838 & $\begin{array}{l}1.07 \\
(0.76 \text { to } \\
1.49)\end{array}$ & 0.709 & $\begin{array}{l}1.17 \\
(0.99 \text { to } \\
1.37)\end{array}$ & 0.070 & $\begin{array}{l}1.23 \\
(1.03 \text { to } \\
1.46)^{\star}\end{array}$ & 0.020 & $\begin{array}{l}0.99 \\
(0.87 \text { to } \\
1.12)\end{array}$ & 0.847 & $\begin{array}{l}1.02 \\
(0.89 \text { to } \\
1.16)\end{array}$ & 0.825 \\
\hline
\end{tabular}

${ }^{*}<0.05 ;{ }^{* \star}<0.01 ;{ }^{* \star *}<0.001$.

${ }^{*}$ Adjusted for age, sex, level of facility, type of health workers, professional ranking and encouragement perceived to report violence in the facility. AOR, adjusted OR.

rather than a problem of criminal behaviour. A survey with policemen showed that when asked by hospitals for assistance to resolve patient-initiated WPV, 55\% refused to go to the scene or reacted too slowly. Policemen who arrived at hospitals in response to reported WPV were often reluctant to intervene in the dispute and sometimes just stood to observe. ${ }^{48}$ Joint efforts by multiple sectors are needed to create an environment where health workers feel safe to work.

Furthermore, $43.2 \%$ of respondents either did not perceive an organisational encouragement to report WPV or were unaware of such a policy. Management models and organisational cultures of public hospitals in China usually emphasise internal and centralised control. ${ }^{49}$ The 
hospital occupies a far more dominant position in both resources and authority than its staffs. This means it is hard that doctors' feedback about their experiences in the workplace will produce concrete results; the hospital makes the rules and doctors are supposed to follow them. ${ }^{50}$ The bureaucratic system enables facilities to be adept at restricting employees' behaviour and encouraging them to tolerate WPV, and leads to their not keen on effectively protecting their employees from WPV or encouraging them to report WPV. ${ }^{8}$ In order to avoid patient-doctor disputes, some hospital administrators even set guidelines which disproportionately punish their own employees in the event of a WPV incident, no matter whether victims are at fault. ${ }^{10}$ It is understandable that staff feels helpless and were ignorant of the organisational encouragement to report. ${ }^{10}$ Consequently, under-reporting and tolerance to WPV may lead to more violent incidents. These findings further indicate inadequate leadership responsibility, lack of training on WPV prevention measures for employees and poor management of aftermaths by health facilities. Campaigns aiming to improve the awareness of WPV and to establish preventive and protective measures at organisational level are urgently needed in China.

Another interesting finding from our study is that victims of WPV rarely reported the incident to medical associations. Only one respondent in our study has chosen these associations as somewhere to report his/her encounter of WPV to. Relevant medical and labour associations are important WPV prevention resources. They play an important role in supporting victims and combatting WPV in health sectors of other countries. ${ }^{351-53}$ Most unions designed policies and procedures to deal with violence, and these materials can be used by employers to train their staff on how to prevent WPV. ${ }^{54-56}$ Nevertheless, such a role of medical and labour unions in the Chinese setting is largely missing. In 2013, the Chinese Medical Doctor association, Chinese Medical Association, Chinese Hospital Association, and China Health Law Society took their first step to announce a joint call for 'zero-tolerance to violence in health sector, ${ }^{57}$ However, follow-up prevention measures and implementation strategies led by these associations are absent. We recommend that professional associations and unions in China take up more accountability and build up systematic capacity to prevent and handle WPV in the health sector.

The study had several limitations. First, this study only investigated hospitals in a highly developed eastern Chinese province, where health services are more accessible and affordable than in less developed regions. It may be partly why we found a lower prevalence of physical violence compared with previous ones. Second, we used a convenience sampling strategy in one province, which may compromise the representativeness of the sample. But we achieved a large sample size of 4862 health workers and a high response rate of $79.8 \%$. Health workers across three tiers of the health system in various cities and counties were recruited for the study. Our study findings still provide new insights and reflect the situation to some extent. Third, we measured Yi Nao at the individual level but Yi Nao incidents are often characterised by gangs gathering and disturbing the hospital for a relatively longer period than a typical momentary violent case. A single Yi Nao incident usually affects a larger number of health workers in the facility. Further research is warranted to measure Yi Nao incidents and the impact at the organisational level. Furthermore, only a small number of the physical violence cases we investigated involved Yi Nao, thereby limiting our understanding of Yi Nao's role in the occurrence of physical violence. Our data suggest, however, a potential link between Yi Nao and higher rates of physical injuries resulting from WPV. To disentangle the role of Yi Nao in physical violence and its consequences, more victim-focused research will be needed. Finally, we excluded other forms of psychological and sexual violence against health workers in this study. Yet this allowed us to gain more insights about the three forms of WPV in China.

\section{CONCLUSION}

Our study found that health workers at higher level care facilities, especially secondary hospitals, had a higher risk of encountering physical violence and threats. More attention to WPV in secondary hospitals is warranted. Preventive measures, such as establishing organisational mechanisms and advocating to report, are urgently needed. Proper handling of violent incidents, including for both victims and perpetrators, are lacking, and tolerance to WPV is widespread. Formal guidelines for preventing and managing the aftermath of WPV are essential. Medical associations have the potential to assume a more active, leading role in tackling WPV in China.

\section{Author affiliations}

${ }^{1}$ Institute for Social and Family Medicine, School of Medicine, Zhejiang University, Hangzhou, China

${ }^{2}$ Faculty of Infectious and Tropical Diseases, London School of Hygiene and Tropical Medicine, London, UK

${ }^{3}$ Center for Global Health, School of Medicine, Zhejiang University, Hangzhou, China ${ }^{4}$ Institute for Global Health, University College London, London, UK

${ }^{5}$ Department of Family Medicine and Primary Care, Li Ka Shing Faculty of Medicine, The University of Hong Kong, Hong Kong, China

Acknowledgements The authors thank the 46 participating health faculties in Zhejiang Province, China for their assistance with data acquisition.

Contributors XDZ, LL and DW conceived and designed the study. SZY and NW collected data. SZY, DW and XDZ analysed the data and drafted the paper. LL, TH, KSS and NW provided constructive comments and revised the manuscript. All authors reviewed and approved the final version of the article.

Funding This study was funded by the Zhejiang University Zijin Talent Program. Competing interests None declared.

Patient consent for publication Not required.

Ethics approval Ethics approval was obtained from the Ethics Committee of Zhejiang University (Approval No ZGL201706-3).

Provenance and peer review Not commissioned; externally peer reviewed. Data availability statement № data are available.

Open access This is an open access article distributed in accordance with the Creative Commons Attribution Non Commercial (CC BY-NC 4.0) license, which 
permits others to distribute, remix, adapt, build upon this work non-commercially, and license their derivative works on different terms, provided the original work is properly cited, appropriate credit is given, any changes made indicated, and the use is non-commercial. See: http://creativecommons.org/licenses/by-nc/4.0/.

\section{REFERENCES}

1. Nelson R. Tackling violence against health-care workers. The Lancet 2014;383:1373-4.

2. Martino D V. Workplace violence in the health sector - country case studies Brazil, Bulgaria, Lebanon, Portugal, South Africa, Thailand, plus an additional Australian study: synthesis report. Geneva ILO/ ICN/WHO/PSI Joint Programme on Workplace Violence in the Health Sector working paper; 2002. https://www.who.int/violence_injury_ prevention/injury/en/WVsynthesisreport.pdf

3. Occupational Safety and Health Administration. Guidelines for preventing workplace violence for healthcare and social service workers. Washington, DC U.S. Department of Labor; 2016.

4. Phillips JP. Workplace violence against health care workers in the United States. N Engl J Med 2016;374:1661-9.

5. Pan Y, Yang Xhong, He JP, et al. To be or not to be a doctor, that is the question: a review of serious incidents of violence against doctors in China from 2003-2013. J Public Health 2015;23:111-6.

6. Shi L, Zhang D, Zhou C, et al. A cross-sectional study on the prevalence and associated risk factors for workplace violence against Chinese nurses. BMJ Open 2017;7:e013105.

7. Xing $\mathrm{K}$, Zhang $\mathrm{X}$, Jiao $\mathrm{M}$, et al. Concern about workplace violence and its risk factors in Chinese township hospitals: a cross-sectional study. Int J Environ Res Public Health 2016;13:811.

8. Yao S, Zeng $\mathrm{Q}$, Peng $\mathrm{M}$, et al. Stop violence against medical workers in China. J Thorac Dis 2014;6:E141-5.

9. Chinese Medical Doctor Association. White paper on the career condition of Chinese licensed physicians, 2015. Available: http:// www.cmda.net/zlwqgzdt/596.jhtml [Accessed 29 Jul 2019].

10. Guan J. Origin and prevention of workplace violence in health care in China: legal and ethical considerations. Chin Med J 2017; 130:1731-6.

11. Teoh RJJ, Lu F, Zhang X-Q. Workplace violence against healthcare professionals in China: a content analysis of media reports. Indian J Med Ethics 2019;4:01-6.

12. Zhang S-E, Liu W, Wang J, et al. Impact of workplace violence and compassionate behaviour in hospitals on stress, sleep quality and subjective health status among Chinese nurses: a cross-sectional survey. BMJ Open 2018;8:e019373.

13. Duan X, Ni X, Shi L, et al. The impact of workplace violence on job satisfaction, job burnout, and turnover intention: the mediating role of social support. Health Qual Life Outcomes 2019;17:93.

14. Zeng Y, Zhang L, Yao G, et al. Analysis of current situation and influencing factor of medical disputes among different levels of medical institutions based on the game theory in Xiamen of China: a cross-sectional survey. Medicine 2018;97:e12501.

15. Lu L, Dong M, Wang S-B, et al. Prevalence of workplace violence against health-care professionals in China: a comprehensive meta-analysis of observational surveys. Trauma Violence Abuse 2018:1524838018774429.

16. Hu Y, Zhang Z. Patient education - a route to improved patient experience in Chinese hospitals? Patient Educ Couns 2015; pii: S0738-3991:30004-5.

17. Harris DM, Wu C-C. Medical malpractice in the people's Republic of China: the 2002 regulation on the handling of medical accidents. $J$ Law Med Ethics 2005;33:456-77.

18. Hesketh T, Wu D, Mao L, et al. Violence against doctors in China. BMJ 2012;345:e5730.

19. Chen Z. Launch of the health-care reform plan in China. The Lancet 2009;373:1322-4.

20. Docherty $M$, Cao $Q$, Wang $H$. Social values and health priority setting in China. J Health Organ Manag 2012;26:351-62.

21. Yip WC-M, Hsiao WC, Chen W, et al. Early appraisal of China's huge and complex health-care reforms. Lancet 2012;379:833-42.

22. Anand S, Fan VY, Zhang JH, et al. Health system reform in China 54 China's human resources for health: quantity, quality, and distribution. Lancet 2008;372:1774-81.

23. Feng Y, Li S, Wu Z. The Study of the Rational Allocation of China's Human Resources for Health. Studies in Asian Social Science $2014 ; 1$.

24. Duan G, Qiu L, Yu W, et al. Outpatient service quality and doctorpatient relationship: a study in Chinese public hospital. International Journal of Services, Economics and Management 2014;6.
25. Horwitz JR. Making profits and providing care: comparing nonprofit, for-profit, and government hospitals. Health Aff 2005;24:790-801.

26. Sun $P$, Zhang $X$, Sun $Y$, et al. Workplace violence against health care workers in North Chinese hospitals: a cross-sectional survey. Int $J$ Environ Res Public Health 2017;14:96.

27. Sun T, Gao L, Li F, et al. Workplace violence, psychological stress, sleep quality and subjective health in Chinese doctors: a large crosssectional study. BMJ Open 2017;7:e017182.

28. Ding Z, Dan LU, Yu S. Impact of patients violence in public hospital on job burnout of nurses. Chinese Hospital Management 2016.

29. Chen X, Lv M, Wang M, et al. Incidence and risk factors of workplace violence against nurses in a Chinese top-level teaching hospital: a cross-sectional study. Appl Nurs Res 2018;40:122-8.

30. Brewster MP. Stalking by former intimates: verbal threats and other predictors of physical violence. Violence Vict 2000;15:41-54.

31. Rasmussen CA, Hogh A, Andersen LP. Threats and physical violence in the workplace: a comparative study of four areas of human service work. J Interpers Violence 2013;28:2749-69.

32. Zhejiang Provincial Bureau of Statistics. Statistics of Zhejiang population in 2017 Zhejiang: Zhejiang provincial Bureau of statistics, 2018. Available: http://tjj.zj.gov.cn/tjgb/rkcydcgb/201801/t20180131 204500.html [Accessed 29 Dec 2018].

33. Health and Family Planning Commission of Zhejiang Province. Quantity of health facilities, hospital beds, and health personnel in Zhejiang Province 2017. Zhejiang Health and Family Planning Commission of Zhejiang Province; 2018. http://www.zjwjw.gov.cn/ art/2018/6/15/art 1202130_18654286.htm

34. Xing $\mathrm{K}$, Jiao $\mathrm{M}, \mathrm{Ma} \mathrm{H}$, et al. Physical violence against general practitioners and nurses in Chinese township hospitals: a crosssectional survey. PLoS One 2015;10:e0142954.

35. Shi L, Wang L, Jia X, et al. Prevalence and correlates of symptoms of post-traumatic stress disorder among Chinese healthcare workers exposed to physical violence: a cross-sectional study. BMJ Open 2017;7:e016810.

36. Li Z, Yan C-mei, Shi L, et al. Workplace violence against medical staff of Chinese children's hospitals: a cross-sectional study. PLoS One 2017;12:e0179373.

37. Kasai Y, Mizuno T, Sakakibara T, et al. A survey of workplace violence against physicians in the hospitals, Myanmar. BMC Res Notes 2018;11:133.

38. Kamchuchat C, Chongsuvivatwong V, Oncheunjit S, et al. Workplace violence directed at nursing staff at a general hospital in southern Thailand. J Occup Health 2008;50:201-7.

39. Hamdan M, Abu Hamra Asma'a. Workplace violence towards workers in the emergency departments of palestinian hospitals: a cross-sectional study. Hum Resour Health 2015;13:28.

40. Morken T, Johansen IH, Alsaker K. Dealing with workplace violence in emergency primary health care: a focus group study. BMC Fam Pract 2015;16:51.

41. Wu D, Lam TP, Lam KF, et al. Doctors' views of patient expectations of medical care in Zhejiang Province, China. Int J Qual Health Care 2017;29:867-73.

42. Zhang L, Stone TE, Zhang J. Understanding the rise of Yinao in China: A commentary on the little known phenomenon of healthcare violence. Nurs Health Sci 2017;19:183-7.

43. Wu D, Lam TP. Underuse of primary care in China: the scale, causes, and solutions. J Am Board Fam Med 2016;29:240-7.

44. Wang N, Wu D, Sun C, et al. Workplace violence in County hospitals in eastern China: risk factors and hospital attitudes. $J$ Interpers Violence 2018;34:886260518792242.

45. Cape J. Consultation length, patient-estimated consultation length, and satisfaction with the consultation. $\mathrm{Br} J$ Gen Pract 2002;52:1004-6.

46. Wyatt R, Anderson-Drevs K, Van Male LM. Workplace violence in health care: a critical issue with a promising solution. JAMA 2016;316:1037-8.

47. Xiang G, Wen Y, Z-k H, et al. Analysis on the Direct Causes and Solutions to "Occupational Medical Quarreler". Journal of North Sichuan Medical College 2011.

48. Zheng X, Wei L, Zhang B, et al. Medical dispute survey in China and medical dispute solution overseas. Chinese Hospitals 2007.

49. Zhou P, Bundorf K, Le Chang J, et al. Organizational culture and its relationship with hospital performance in public hospitals in China. Health Serv Res 2011;46:2139-60.

50. Yuan Q, Peng W. The Five "Important and Light"Construction Analysis of Public Hospital Management Culture- from the Perspectives of Social Field and Habituation. Modern Hospital 2018;18:188-90

51. Morrison JL, Lantos JD, Levinson W. Aggression and violence directed toward physicians. J Gen Intern Med 1998;13:556-61. 
52. American Medical Association. Taking steps to prevent violence in health care workplace Chicago: American Medical association, 2016. Available: https://wire.ama-assn.org/ama-news/taking-stepsprevent-violence-health-care-workplace [Accessed 29 Dec 2018].

53. Richards J. ILO/ICN/WHO/PSI workplace violence in the health sector Cross-Cutting theme study: management of workplace violence victims. Geneva International Labour Office, International Council of Nurses, World Health Organisation, Public Services International; 2003.

54. American Federation of State CaME. Preventing workplace violence: a Union representative's Guidebook, 2006. Available: https://www. afscme.org/news/publications/for-leaders/preventing-workplaceviolence-a-union-representatives-guidebook [Accessed 29 Dec 2018]

55. UNISON. Violence at work, a guide to risk prevention. London UNISON; 1997

56. UNISON. It's not part of the job: a health and safety guide on tackling violence at work. London UNISON; 2013.

57. Chinese Medical Doctor Association. A joint call for zero tolerance to workplace violence against health workers by Chinese medical doctor association, Chinese medical association, Chinese Hospital association, and China health law Society (Chinese). Otorhinolaryngology 2013;28. 